\title{
Basis of Changes in Left-Right Coordination of Rhythmic Motor Activity during Development in the Rat Spinal Cord
}

\author{
Kiyomi Nakayama, ${ }^{1,2}$ Hiroshi Nishimaru, ${ }^{1}$ and Norio Kudo ${ }^{1}$ \\ 1Department of Physiology, Institute of Basic Medical Sciences, University of Tsukuba, Tsukuba, Ibaraki 305-8575, Japan, \\ and ${ }^{2}$ Center for Medical Sciences, Ibaraki Prefectural University of Health Sciences, Ami, Ibaraki 300-0394, Japan
}

The basic neuronal networks generating coordinated rhythmic motor activity, such as left-right alternate limb movement during locomotion in mammals, are located in the spinal cord. In rat fetuses, the spatial pattern of the rhythmic activity between the left and right sides is synchronous at and shortly after rhythmogenesis before the pattern becomes alternate by birth. The neuronal mechanisms underlying these developmental changes in the leftright coordination were examined in isolated spinal cord preparations. Calcium imaging of commissural neurons at the early fetal stages revealed that the intracellular $\mathrm{Ca}^{2+}$ concentration of the commissural neurons was elevated by bath-application of 5-hydroxytryptamine (5-HT) in synchrony with the simultaneously recorded rhythmic activity of the ventral root, suggesting that the commissural neurons mediate the left-right coordination of the rhythmic activity from onset of the rhythmogenesis. Using a lon- gitudinal split-bath setup, we show that the synchronicity in pattern of the rhythmic activity is the result of excitatory connections being formed via commissural neurons between the rhythmgenerating networks located in the left and right spinal cord. During this period, such connections were found to be mediated by excitatory synaptic transmission via $\mathrm{GABA}_{\mathrm{A}}$ receptors. When the pattern of rhythmic activity became left-right alternate at later fetal stages, these connections, still via GABA $_{A}$ receptors, were mediating reciprocal inhibition between the two sides. Nearer birth, glycine receptors took over this role. Our results reveal the nature of the neuronal mechanisms forming the basis of the left-right coordination of rhythmic motor activity during prenatal development.

Key words: $G A B A_{A}$ receptor; commissural neuron; locomotion; development; spinal cord; rat fetus; imaging
Glycine and GABA have been known to be major inhibitory neurotransmitters in the mammalian spinal cord (Davidoff and Hackman, 1983; Young and MacDonald, 1983). In the neuronal networks generating motor activity, these amino acids provide the fast synaptic inhibition that is essential for coordination between antagonistic muscles and between left and right limbs (Cowley and Schmidt, 1995; for review, see Kiehn et al., 1997). However, because GABA and glycine may transiently have a depolarizing or excitatory action both in the immature spinal cord (Wu et al., 1992; Nishimaru et al., 1996) and in other parts of the CNS (Ben-Ari et al., 1989; Ehrlich et al., 1999), their functional roles in developing spinal networks are not yet fully understood.

Coordinated movements of the left and right limbs are one of the main features of locomotor activity in quadrupeds and bipeds. The basic motor patterns underlying rhythmic limb movements during locomotion in these animals are generated by neuronal networks located within the spinal cord (for review, see Grillner, 1975, 1985). One experimental model used extensively to study this network is the isolated spinal cord preparation taken from neonatal rats (Kudo and Yamada, 1987; Smith and Feldman, 1987; Cazalets et al., 1992; Kiehn and Kjaerulff, 1996). Bath application of various neuroactive substances, including 5-hydroxytryptamine (5-HT), to

\footnotetext{
Received March 12, 2002; revised Sept. 10, 2002; accepted Sept. 12, 2002.

This study was supported by the Ministry of Education, Science, Sports and Culture of Japan with a Grant in Aid for Scientific Research. K.N. thanks the Japanese Society for the Promotion of Science for a Young Scientist Fellowship. We thank Dr. Miyuki Yamamoto and Dr. Akihiro Yamanaka for valuable comments on this manuscript. We also thank Akiko Ohgami for technical assistance.

Correspondence should be addressed to Dr. Hiroshi Nishimaru, Department of Physiology, Institute of Basic Medical Sciences, University of Tsukuba, Tennodai 1-1-1, Tsukuba, Ibaraki 305-8575, Japan. E-mail: nishimar@md.tsukuba.ac.jp. Copyright (C) 2002 Society for Neuroscience 0270-6474/02/2210388-11\$15.00/0
}

this preparation can induce reciprocal rhythmic activity in the left and right hindlimb muscles, or in the lumbar ventral roots, that resembles the natural locomotor activity seen in these animals. Studies using such preparations have revealed that the principal elements of the network generating these highly coordinated patterns are formed during the fetal period (for review, see Nishimaru and Kudo, 2000). However, at the time of onset of coordinated rhythmic activity (a week before birth in rats), a synchronized pattern can be observed between the left and right sides that is distinct from the pattern seen in the neonatal spinal cord (Ozaki et al., 1996; Iizuka et al., 1998). The nature of the neuronal mechanisms underlying this synchronized pattern remains unclear, as does the way it develops.

Here we demonstrate that from the time of onset of the rhythmic activity, commissural neurons sending their axons through the ventral commissure connect the rhythm-generating networks located in the left and right sides of the spinal cord. Our results indicate that during this period, the synchronized rhythmic activity between the two sides is generated by excitatory transmission mediated by $\mathrm{GABA}_{\mathrm{A}}$ receptors. However, the functional role of GABAergic synaptic transmission changes from excitatory to inhibitory in parallel with the change in pattern from left-right synchronous to left-right alternate. Finally, after the pattern has become alternate, glycinergic synaptic transmission becomes the major inhibitory component in this commissural pathway.

Parts of this study have been published previously in abstract form (Nakayama et al., 2001a).

\section{MATERIALS AND METHODS}

Isolated spinal cord preparation. All experiments were performed with the approval of the Animal Research Committee of the University of 
Tsukuba, which operates in accordance with Japanese Governmental Law (No. 105). Experiments were performed on fetal Wistar rats aged between embryonic day (E) 15.5 and 20.5 and newborn rats aged postnatal day 0 . The day on which spermatozoa were found in the female rat's vaginal smear was taken as E0.5. The gestation period was usually $22.5 \mathrm{~d}$. The spinal cord was obtained as described previously (Nishimaru et al., 1996). In brief, pregnant rats were deeply anesthetized with ether and then decapitated. Fetuses were removed by Cesarean section and decapitated. They were then eviscerated in a dissection chamber filled with ice-cold oxygenated $\left(95 \% \mathrm{O}_{2}+5 \% \mathrm{CO}_{2}\right)$ Krebs' solution of the following composition (in $\mathrm{mM}$ ): $\mathrm{NaCl} 118.4, \mathrm{KCl} 4.69, \mathrm{CaCl}_{2} 2.52, \mathrm{MgSO}_{4} 1.25$, $\mathrm{NaHCO}_{3} 25.0, \mathrm{KH}_{2} \mathrm{PO}_{4}$ 1.18, D-glucose, 11.1. The spinal cord was isolated from the lower thoracic or upper lumbar to the sacral level.

Ventral root recording. The spinal cord was obtained together with the left and right ventral roots of the lumbar segments. The isolated spinal cord was placed in a recording chamber and pinned down to the siliconerubber floor with the ventral side upward. All experiments were performed under a constant flow $(3-5 \mathrm{ml} / \mathrm{min})$ of Krebs' solution at room temperature $\left(24-26^{\circ} \mathrm{C}\right)$. The lumbar ventral roots on the left and right sides were incorporated into glass suction electrodes. The motor activity in the ventral roots was amplified using AC-coupled amplifiers (gain: 10 k; bandpass filter: $15 \mathrm{~Hz}-3 \mathrm{kHz}$; Nihon Kohden, Tokyo, Japan). All recordings were stored on a magnetic tape using a PCM data recorder (Sony, Tokyo, Japan) for off-line analysis. Raw records and integrated records $(0.5 \mathrm{sec}$ time constant) were monitored using a thermal array printer (Nihon Kohden).

Retrograde labeling of commissural neurons. The dorsal commissure of the dissected lumbar spinal cord was split, and the cord was immersion fixed in $4 \%$ paraformaldehyde in $0.1 \mathrm{M}$ phosphate buffer, $\mathrm{pH} 7.4$, for 1-2 d. Small crystals of the lipophilic tracer 1,1'-dioctadecyl-3,3,3',3'tetramethylindocarbocyanine perchlorate (DiI; Molecular Probes, Eugene, OR) were placed on the ventral horn on one side of L1 segment for labeling of commissural neurons with ascending axons (see Fig. $3 E$ ). The preparations were then returned to the fixative and incubated at $37^{\circ} \mathrm{C}$ for 35-80 d. After this incubation, the preparations were washed with phosphate buffer and then sectioned on a Vibratome (Series 1000; Technical Products International, St. Louis, MO) at $100 \mu \mathrm{m}$ for inspection of serial sections. The number of $100-\mu \mathrm{m}$-thick sections was four to five per spinal segment. Photomicrographs were taken of selected sections using Fujichrome 400 ASA film (Fuji Film, Tokyo, Japan). Selected transparencies were scanned into Adobe Photoshop (version 5.0; Adobe Systems, Mountain View, CA) in a Power Macintosh computer (Apple Computers, Cupertino, CA) by way of a Polaroid SprintScan 35 (Polaroid, Cambridge, MA). Images were taken of all sections using a CCD camera (Olympus, Tokyo, Japan) and a Power Macintosh computer. The number of cells was counted using these images.

Calcium imaging of commissural neurons. To label the commissural neurons with calcium-sensitive dye, Calcium Green-1 AM (Molecular Probes; $50 \mu \mathrm{g}$ ) was dissolved in dimethyl sulfoxide $(5 \mu \mathrm{l})$ containing Pluronic F-127 $(30 \mu \mathrm{g})$ and then dispersed in Krebs' solution $(10 \mu \mathrm{l})$ (Koshiya and Smith, 1999). The isolated lumbar spinal cord was transected at the mid-lumbar level using a rotating-blade slicer (Rotorslicer; Dosaka, Kyoto, Japan). The Calcium Green-1 AM solution was microinjected by way of a glass pipette ( $10 \mu \mathrm{m}$ tip diameter) inserted via the transected surface into the motor nucleus contralateral to the side to be imaged (see Fig. 4A). Calcium Green-1 AM will diffuse along axons and retrogradely label the cell bodies of contralateral commissural neurons (see Fig. 4A). After incubation for $7-15 \mathrm{hr}$, the spinal cord was placed in the recording chamber. We visualized Calcium Green-labeled neurons using an inverted microscope (IX70; Olympus) fitted with a 75 W xenon lamp, optical filters (excitation filter, 475-495 nm; emission filter, $515-550 \mathrm{~nm})$, and either a dry objective [20×, 0.75 numerical aperture (NA); Olympus] or a water-immersion objective $(40 \times, 1.15 \mathrm{NA}$; Olympus). Fluorescence images were captured into an intensified CCD camera (Photonic Science, Robertsbridge, UK). The fluorescence intensity of labeled commissural neurons was recorded simultaneously with ventral root recordings (see Fig. 4C); the fluorescence intensity was imaged using Quanti Cell 700 (Applied Imaging, Newcastle, UK). Images were acquired at a frequency of $1 \mathrm{~Hz}$.

Longitudinal split-bath preparation. The isolated lumbar spinal cord, with the dorsal commissure cut, was set into a split-bath recording chamber (see Fig. 5A). In the split-bath chamber, a latex membrane served as a way of separating the left and right sides. The spinal cord was fixed, with the ventral surface upward, through a narrow slit made in this latex wall (see Fig. 5A). Motor activity was recorded from the left and right ventral roots in each case. At the end of the experiment, the effective separation of the two half-chambers was confirmed by adding Fast Green FCF (Merck KGaA, Darmstadt, Germany) to the solution that perfused one side and looking for leakage to the contralateral half-chamber.

Data analysis. The coupling strength between the left and right side after lesions and pharmacological treatment was analyzed using circular statistics (Batschelet, 1981; Kjaerulff and Kiehn, 1996). The phase values of 10 left-side burst onsets from each preparation were calculated with regard to right-side onsets, and the values were plotted on a circle representing the interval of possible phases from 0 to 1 . The phase values 0 and 1 are equivalent and reflect synchrony, whereas 0.5 is equivalent to alternation. The mean phase and the measure $r$, which describes the concentration of phase values around the mean, were shown by the vector originating from the center of the circle. Using the Rayleigh test (Batschelet, 1981), we determined whether the concentration $r$ of phases around the mean was sufficiently high to state that coupling was present. The coupling was considered significant when the Rayleigh test resulted in $p<0.001$. Multisample testing of the angles was performed using the Watson-Williams test (Batschelet, 1981) to compare between the resultant mean phase values; $p<0.001$ was taken to indicate significance.

Data in calcium imaging and bath separation are given as mean \pm SE. The significance of differences was determined using a Student's $t$ test; $p<0.01$ was taken to indicate significance.

\section{RESULTS}

Bath application of 5-HT induced rhythmic activity in the lumbar ventral roots at and after E14.5. As shown in integrated records, the pattern of 5-HT-induced rhythmic activity between the left and right lumbar ventral roots was synchronous at E14.5-16.5 (Fig. 1A, E16.5) before becoming alternate by E18.5-20.5 (Fig. $1 B, E 20.5)$.

\section{Pathways coordinating left-right motor activity at the early fetal stages}

To examine the pathways responsible for synchronizing rhythmic activity between left and right during the early fetal period, the effects of lesions of the dorsal and ventral commissure were examined at E15.5. After mid-sagittal lesion of the dorsal spinal cord (Fig. $2 \mathrm{~A}$ ) along the whole rostrocaudal extent of the isolated spinal cord, rhythmic activity could still be induced in both left and right ventral roots. Moreover, the synchronicity between the two sides was not changed by the lesion $(n=5)$ (Fig. $2 B)$. On the other hand, after mid-sagittal lesion of the ventral spinal cord (Fig. 2A) along the whole rostrocaudal extent of the isolated spinal cord, rhythmic activity could still be observed, but the two sides were uncoupled $(n=5)$ (Fig. $2 C$ ), suggesting that there are independent neuronal networks generating rhythmic activity, one on each side of the spinal cord.

\section{Activity of commissural neurons during rhythmic activity}

The above results also suggest that spinal neurons that send their axons to the contralateral side through the ventral commissure (i.e., commissural neurons) are crucial for the coordination of rhythmic activity between left and right sides of the spinal cord during the early fetal period. We labeled such commissural neurons by placing crystals of DiI unilaterally on the ventral horn of the isolated spinal cord at E15.5-16.5. DiI-labeled commissural neurons were observed up to the L6 segment (21-24 sections, 100 $\mu \mathrm{m}$ thickness). Figure $3 A$ shows a transverse section of a spinal cord labeled in this way. The cell bodies of commissural neurons were located in the medial (Fig. 3B) and lateral (Fig. $3 C$ ) parts of the intermediate zone and in the medial part of the ventral horn (Fig. 3D). The cell bodies of all the labeled commissural neurons in one preparation were plotted in the transverse plane (Fig. $3 F$ ). Approximately $90 \%$ of these cell bodies were located in the 
A

E16.5
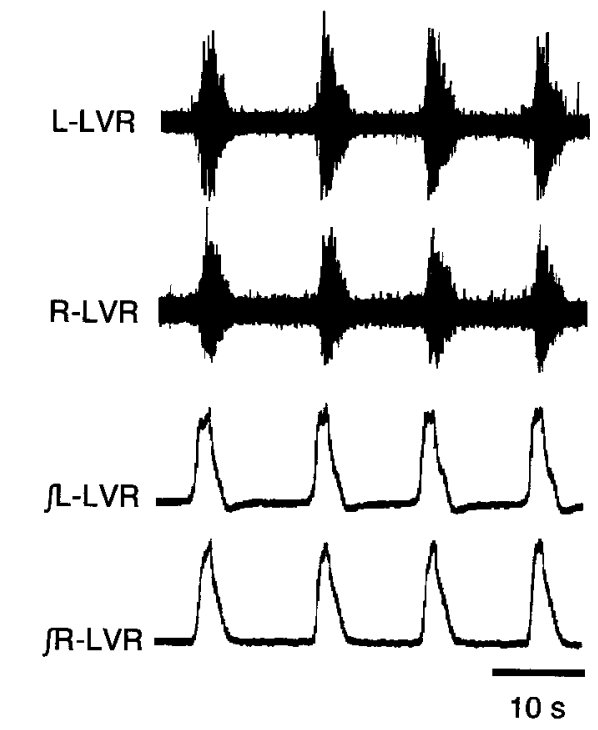

B

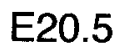

L-LVR

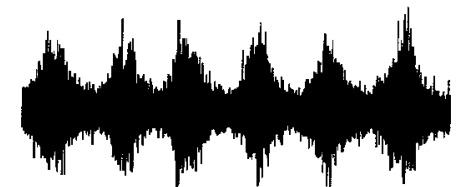

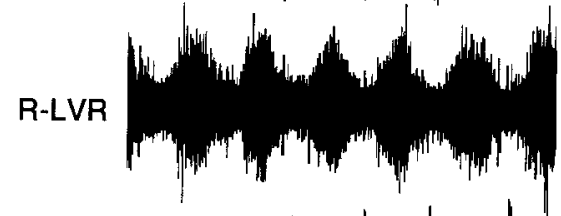

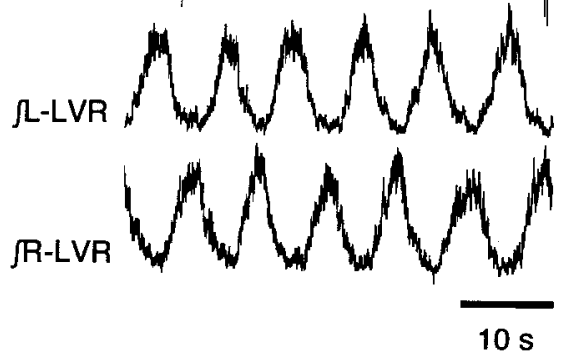

Figure 1. Pattern of rhythmic activity induced by 5-HT in left and right lumbar ventral roots of fetal rat spinal cord. Nerve discharges recorded simultaneously from the left and right lumbar ventral roots (top traces) and their integrals (bottom traces) at E16.5 $(A)$ and E20.5 $(B)$ are shown. The rhythmic activity was induced by $1 \mu \mathrm{M} 5-\mathrm{HT}$ at E16.5 and by $20 \mu \mathrm{M}$ 5-HT at E20.5. The pattern of the 5-HT-induced rhythmic activity was the same at all concentrations $(1-30 \mu \mathrm{M})$ examined.

medial part of the intermediate zone and the medial part of the ventral horn. Similar results were obtained in all six preparations examined.

To examine whether these commissural neurons are involved in coordinating rhythmic activity between the left and right sides of the spinal cord, we used a calcium-imaging technique to visualize the activity of commissural neurons at E16.5. Calcium Green-1 AM, a membrane-permeant calcium-sensitive dye, was injected unilaterally into the ventral horn, from where it was taken up by axons and transported retrogradely to cell bodies of commissural
A
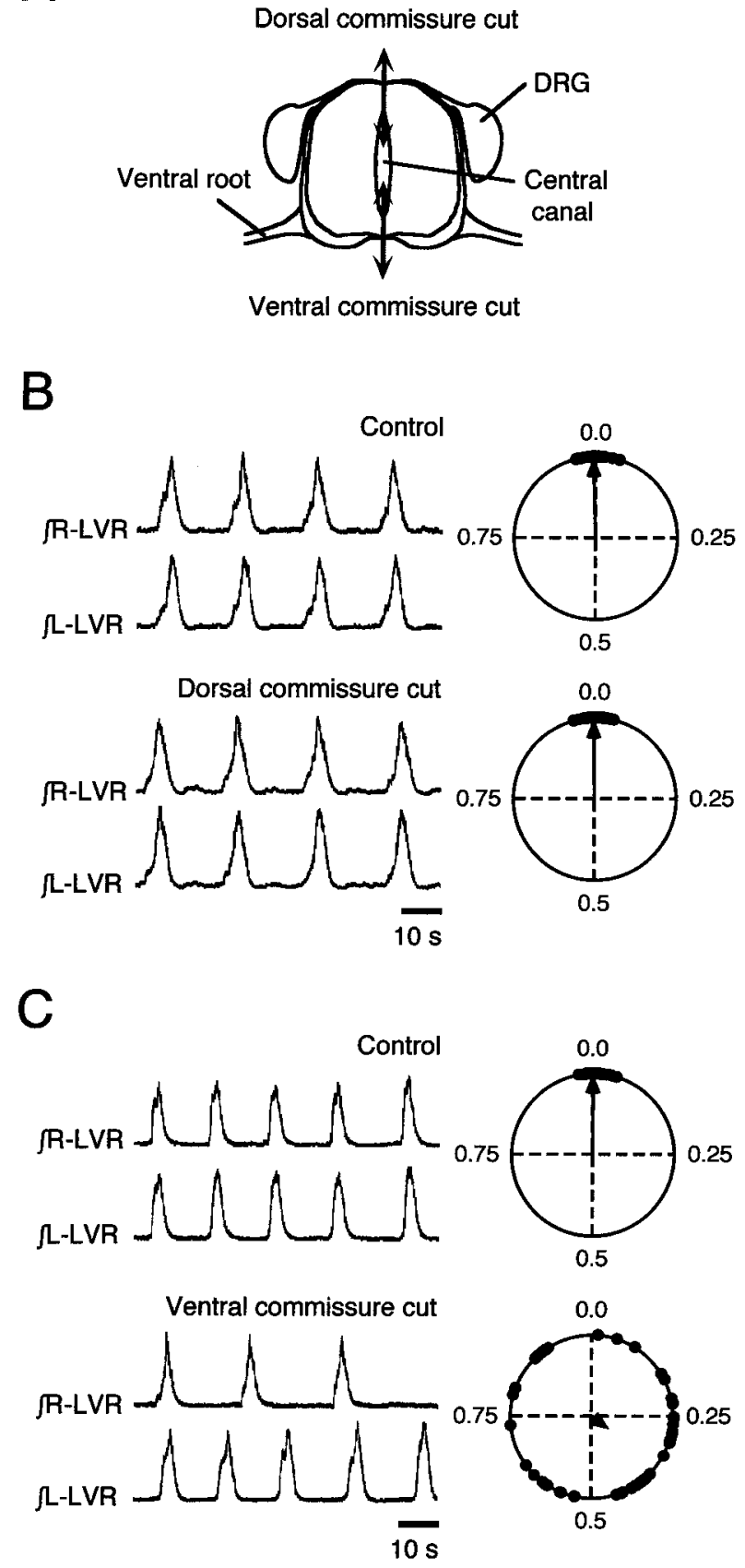

Figure 2. Effects of lesions of dorsal and ventral commissures on 5-HTinduced rhythmic activity at E15.5. A, Schematic drawing of the lesion of the dorsal commissure (top arrow) and ventral commissure (bottom arrow). $B$, Ventral root discharges induced by $1 \mu \mathrm{M} 5$-HT before (top traces) and after (bottom traces) lesion of the dorsal commissure in a single preparation. $C$, Ventral root discharges induced by $1 \mu \mathrm{M}$ 5-HT before (top traces) and after (bottom traces) lesion of the ventral commissure in a single preparation. $B, C$, Right panels show phase lags between the left and right sides. The circular plot is based on 10 phase values from each preparation. Data from five tested preparations were pooled and displayed as the left-right circular phase diagram. There were no significant differences among the five preparations.

neurons on the opposite side (Fig. 4A). These cell bodies were localized mainly in the medial part of the intermediate zone and in the medial part of the ventral horn (Fig. $4 B$ ), a location similar to that of the DiI-labeled commissural neurons (Fig. $3 F$ ), indi- 

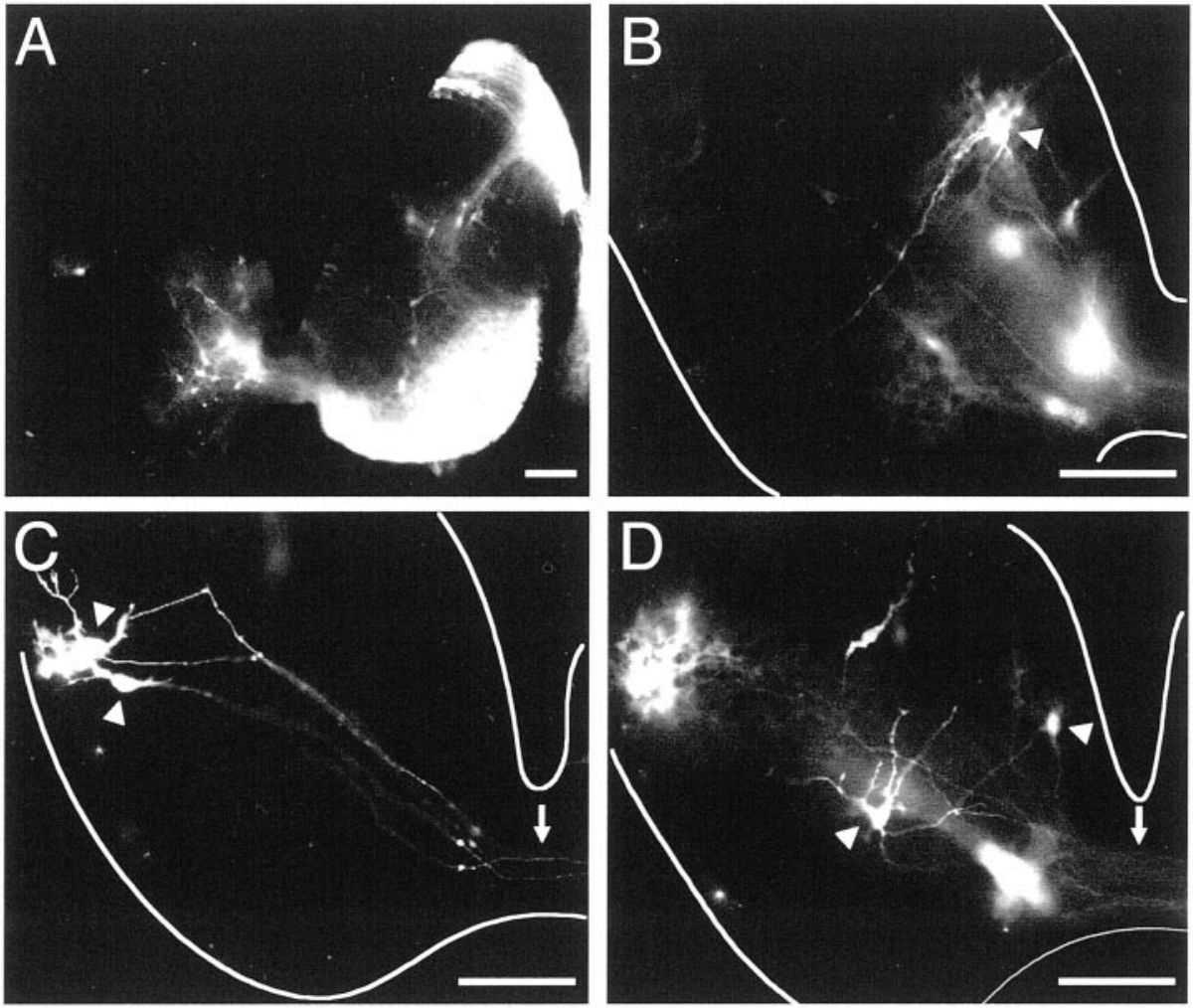

$E$
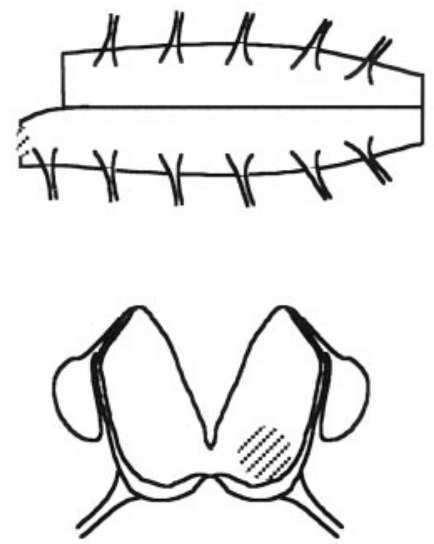
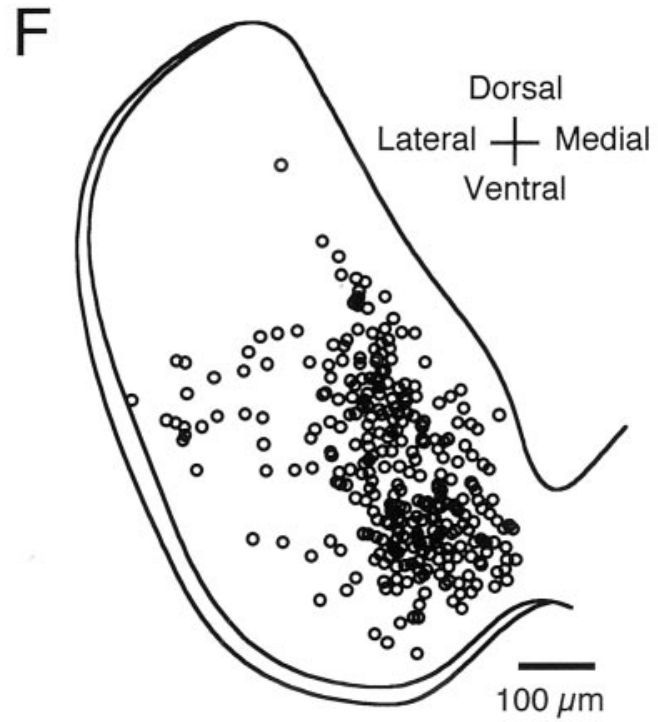

Figure 3. Commissural neurons retrogradely labeled with DiI. $A-D$, Fluorescent lightmicroscope photographs taken from transverse sections of the lumbar spinal cord at E15.5. A, Cell bodies of commissural neurons were labeled on the side (left) contralateral to the DiI-injected side (right). $B-D$, Commissural neurons located in the medial $(B)$ and lateral $(C)$ parts of the intermediate zone and in the medial part of the ventral horn $(D)$ are shown. Arrowheads and arrows show, respectively, cell bodies of commissural neurons and axons crossing to the contralateral side. $E$, The dyeinjection site is shown in the horizontal plane (top) and in the transverse plane (bottom). To label only the commissural neurons crossing the ventral commissure, the dorsal commissure was cut. To prevent nonspecific diff usion of DiI, one segment was cut away on the contralateral side before placement of DiI. Crystals of DiI were placed in the hatched area. $F$, Location of all the labeled commissural neurons in a preparation at E16.5. Cell bodies are shown by open circles in the transverse plane. Scale bars: $A-D$, $F, 100 \mu \mathrm{m}$. cating that the neurons labeled by Calcium Green-1 AM and those labeled using DiI form part of the same population of cells. Figure 4, $D$ and $E$, shows representative Calcium Green-labeled commissural neurons observed on the side opposite the dyeinjected side. Fluorescence intensity, which indicates intracellular free $\mathrm{Ca}^{2+}$ concentration $\left(\left[\mathrm{Ca}^{2+}\right]_{\mathrm{i}}\right.$ ), in labeled neurons was measured simultaneously with recordings of ventral root activity. Bath application of 5-HT $(1 \mu \mathrm{M})$ induced a rhythmic $\left[\mathrm{Ca}^{2+}\right]_{\mathrm{i}}$ elevation in $\sim 80 \%$ of labeled neurons (mean $80.4 \pm 1.7 \% ; 214$ cells, 7 preparations). This rhythmic $\left[\mathrm{Ca}^{2+}\right]_{i}$ elevation was synchronous with the motoneuronal activity (Fig. $4 F$ ). These results suggest that these commissural neurons are candidates for the neurons sending signals from the rhythm-generating network on one side to the other side of the spinal cord, and thus they are likely to mediate the left-right coordination of the 5-HT-induced synchronous rhythmic activity seen in the spinal cord at the early fetal stages.

\section{Commissural inputs from one side of the spinal cord to the contralateral motoneurons}

We hypothesized from the above result that the commissural neurons in question activate the rhythm-generating network on the contralateral side. To examine this hypothesis, the rhythmgenerating network on one side of the E15.5 spinal cord was excited selectively using a longitudinal split-bath setup (Fig. 5A), which was developed by Kjaerulff and Kiehn (1997), and the effects evoked on the opposite side were observed by means of ventral root recording. In this setup, the only connection between 
A

\section{Micro-injection \\ Calcium Green-1 AM}

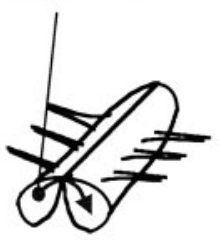

Incubate for 7-15 h
B

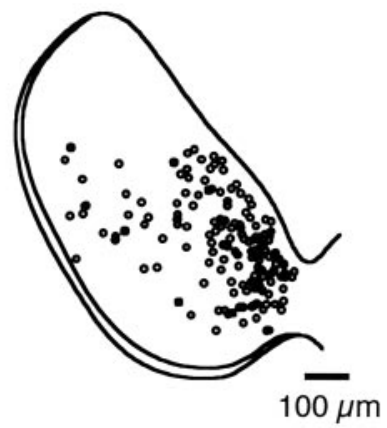

Figure 4. Calcium imaging of commissural neurons. $A$, Schematic drawing of injection site for Calcium Green-1 AM. The arrow indicates retrograde labeling of contralateral commissural neurons. B, Location of commissural neurons labeled by Calcium Green-1 AM at E16.5. The locations of cell bodies were plotted from transverse sections of a preparation after a $10 \mathrm{hr}$ incubation $(n=3)$. $C$, Scheme of the experimental setup for calcium imaging and simultaneous ventral root recording. The spinal cord was put in a chamber with the rostral cut surface down. $D$, Low-power image of Calcium Green-labeled commissural neurons in transected surface after a $10 \mathrm{hr}$ incubation after dye injection at E16.5. The neurons within the box are shown at higher magnification $(40 \times$ objective) in $E . F$, Fluorescence change $(\Delta F / F)$ in the three neurons indicated by circles in $E$. Rhythmic elevations in fluorescence intensity were induced by application of $1 \mu \mathrm{M}$ 5-HT (as shown by the bar). The bottommost trace shows integrated ventral root discharges (recorded simultaneously). During such rhythmic elevations in fluorescence intensity, the peak amplitude rose by $24.8 \pm 0.9 \%$ compared with the baseline fluorescence intensity (174 cells, 7 preparations), and the mean duration of a single elevation was $11.2 \pm 0.2 \mathrm{sec}(174$ cells, 7 preparations).

C

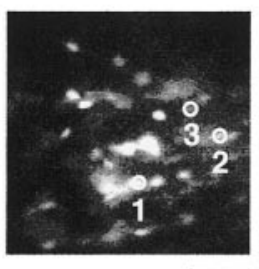

$50 \mu \mathrm{m}$

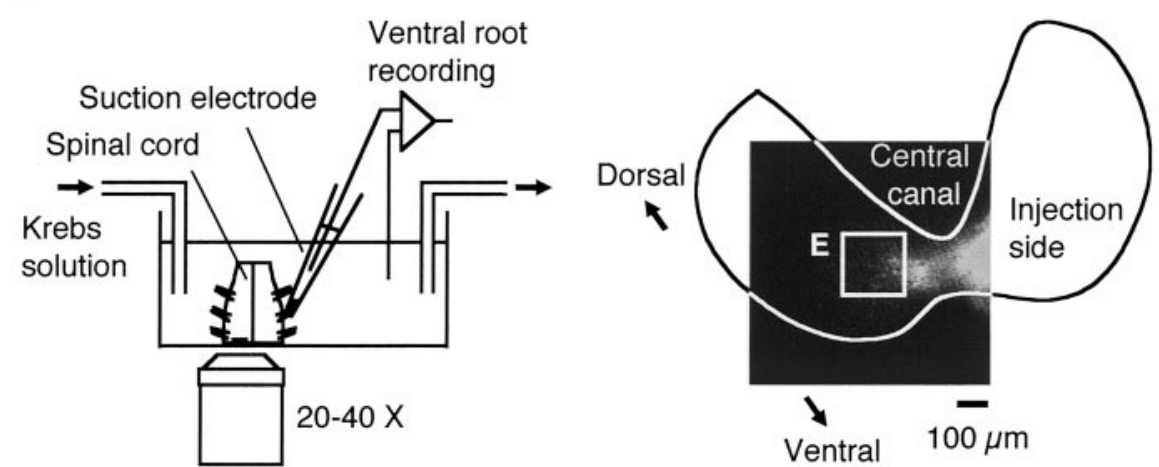

$E$

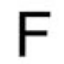

the two half-chambers is via the ventral commissure. When 5-HT $(1 \mu \mathrm{M})$ was applied to one side of the spinal cord, synchronous rhythmic activity was induced in the ventral roots of both sides $(n=10)$ (Fig. 5B). The rhythmic activity induced on the 5-HTfree side was blocked by perfusion of $\mathrm{Ca}^{2+}$-free Krebs' solution to that side $(n=5)$ (Fig. $5 C)$, indicating that the activity was evoked by synaptic inputs from the 5HT-applied side. Moreover, removing $\mathrm{Ca}^{2+}$ from the 5HT-applied side abolished the synchronous activity on both sides $(n=3)$ (Fig. $5 C$ ). These observations indicate that commissural neurons receive synaptic inputs from the rhythm-generating network on the ipsilateral side and mediate them via synaptic transmission to the other side, which should play an important role in synchronizing the rhythmic activity between the left and right side. These results also suggest that inputs from the commissural neurons are capable of generating rhythmic activity on the contralateral side. To examine the effect of direct stimulation of the commissural neurons on the contralateral rhythm-generating network, we used muscimol, a $\mathrm{GABA}_{\mathrm{A}}$ receptor agonist that can strongly depolarize and excite spinal neurons during this period (Reichling et al., 1994; Li et al., 1998; Kulik et al., 2000). It has been shown that in the presence of tetrodotoxin (TTX), activation of $\mathrm{GABA}_{\mathrm{A}}$ receptors induces $\left[\mathrm{Ca}^{2+}\right]_{\mathrm{i}}$ elevation via the voltage-dependent calcium channel in neurons in the slices of immature rat CNS, including neonatal Purkinje cells (Eilers et al., 2001), neonatal hippocampal neurons (Leinekugel et al., 1995), and fetal lumbar motoneurons (Kulik et al., 2000). In the isolated spinal cord preparation (Fig. 4A-C), brief application (duration $30 \mathrm{sec})$ of muscimol $(100 \mu \mathrm{M})$ with TTX $(1 \mu \mathrm{M})$ induced a $\left[\mathrm{Ca}^{2+}\right]_{\mathrm{i}}$ elevation that lasted for $>3 \mathrm{~min}$ in commissural neurons (Fig. $5 D$ ). Such $\left[\mathrm{Ca}^{2+}\right]_{\mathrm{i}}$ elevation was blocked by perfusion of $\mathrm{Ca}^{2+}$-free Krebs' solution $(n=6$; data not shown). Therefore, we applied this method to stimulate commissural neurons in the longitudinal split-bath setup. Brief application (duration $30 \mathrm{sec}$ ) of muscimol $(100 \mu \mathrm{M})$ with $\mathrm{Ca}^{2+}$ - 
A

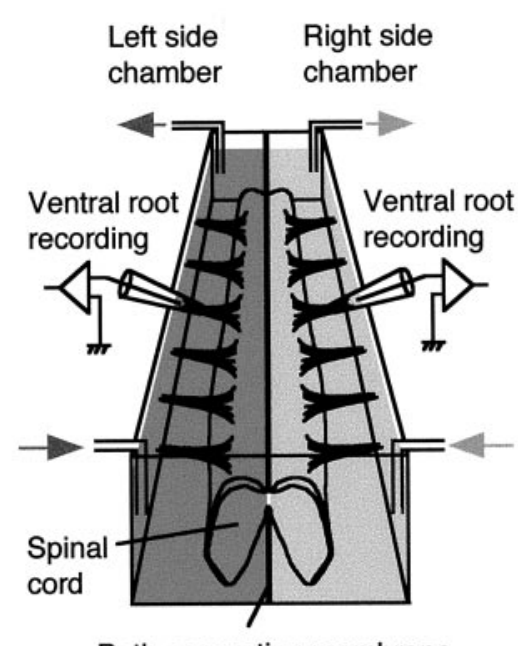

Bath-separating membrane
B
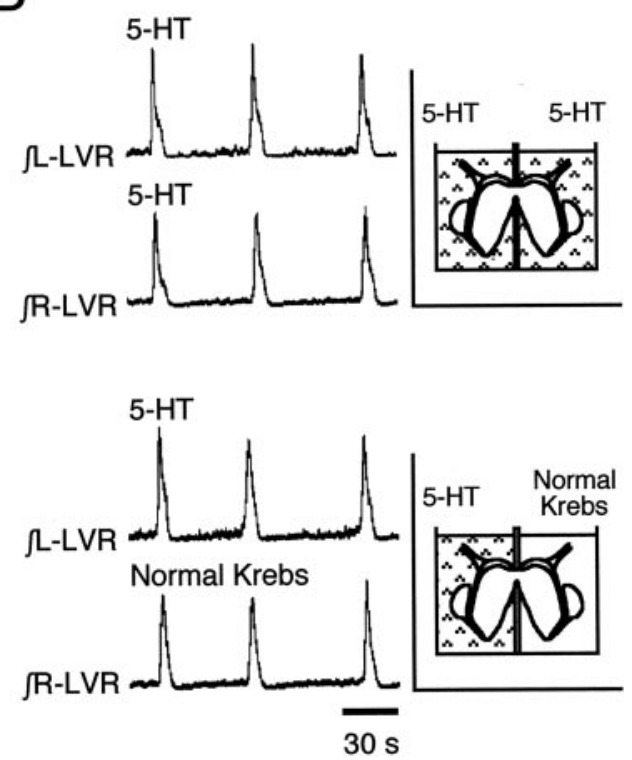

C

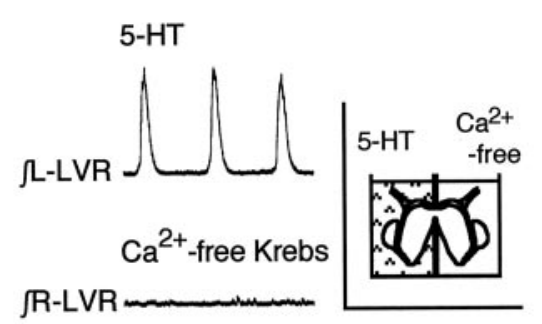

D

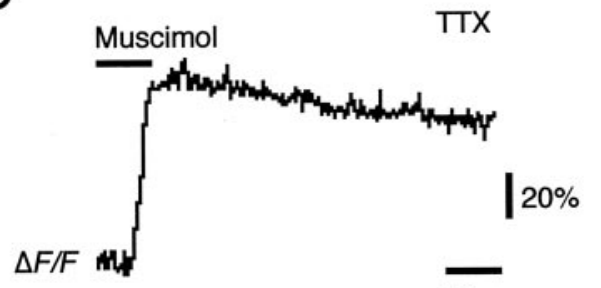

$30 \mathrm{~s}$

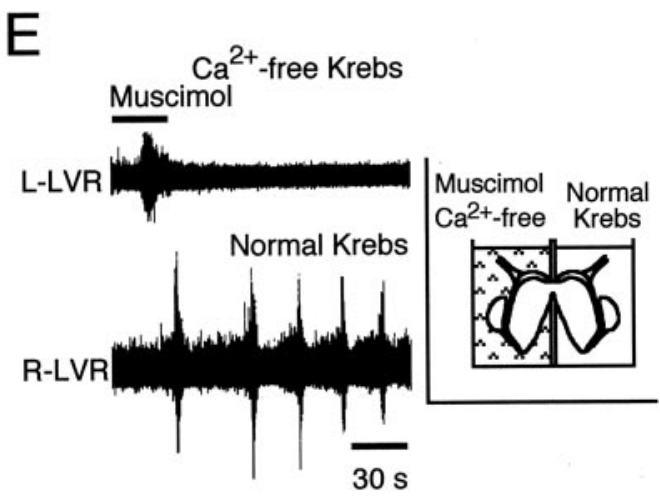

Figure 5. Rhythmic activity induced in contralateral ventral root by excitation of the rhythm-generating network or commissural neurons on one side of E15.5 spinal cord. $A$, Scheme of the longitudinal split-bath setup. The chamber was separated into left and right parts, with the only connection via the ventral commissure of the spinal cord. $B$, Integrated recording of the rhythmic activity induced by perfusion with $1 \mu \mathrm{M} 5$-HT on both sides (top) or on one side (the left) (bottom) in the longitudinal split-bath setup. $C$, Effects of perfusion of $\mathrm{Ca}^{2+}$-free Krebs' solution on the 5-HT-free side (top) and on the 5-HT-applied side (bottom). D, Effect of application of muscimol to the commissural neurons examined using calcium imaging. The commissural neurons were labeled with Calcium Green-1 AM as shown in Figure 4 . The fluorescence intensity was elevated by application of $100 \mu \mathrm{M}$ muscimol in the presence of $1 \mu \mathrm{M}$ TTX. $E$, Activity in the left and right ventral roots during application of $100 \mu \mathrm{M}$ muscimol to the side also exposed to $\mathrm{Ca}^{2+}$-free Krebs' solution (as shown in the schematic drawing in the inset). free Krebs' solution on one side evoked rhythmic activity in the ventral root on the opposite side (which was being perfused by normal Krebs' solution) (Fig. 5E). The latent period between muscimol application and the onset of the rhythmic activity $(33.6 \pm 1.8 \mathrm{sec} ; n=6)$ was similar to the time it took to tonically activate the commissural neurons in calcium imaging experiments $(30.7 \pm 0.6 \mathrm{sec} ; n=27)$ (Fig. 5D). The frequency $(0.060 \pm 0.009$ $\mathrm{Hz} ; n=6)$ and the burst duration $(4.8 \pm 1.3 \mathrm{sec} ; n=6)$ of the rhythmic activity evoked on the opposite side were within the range associated with 5-HT-induced rhythmic activity (Nakayama et al., 2001b). No rhythmic activity was evoked in the ventral root on the muscimol-applied side, although a single burst was observed, which is likely to be caused by direct excitation of motoneurons (Fig. 5E). These results indicate that sustained excitation of the commissural neurons is capable of activating the rhythm-generating network on the opposite side.
It has been shown that synaptic transmission via glutamate, glycine, and $\mathrm{GABA}_{\mathrm{A}}$ receptors is involved in the neuronal networks that generate spinal reflexes (Wu et al., 1992) and rhythmic motor activity (Nishimaru et al., 1996; Nakayama et al., 2001b) during the fetal period. However, it is unclear whether these neurotransmitters mediate the left-right coordination of the rhythm as well. We examined the effects of antagonists of these receptors on the rhythmic activity induced on one side by application of 5-HT to the opposite side of the E15.5 spinal cord in a longitudinal split-bath setup (Fig. $6 A-E$ ). In all preparations examined, the amplitude of the bursts of rhythmic activity on the 5-HT-free side was unaffected by application of kynurenate (4 $\mathrm{mm})$, an ionotrophic glutamate receptor antagonist $(n=5)$ (Fig. $6 B, F)$. Blockade of glycine receptors by bath-application of strychnine $(5 \mu \mathrm{M})$ to the 5 -HT-free side partially blocked the rhythmic activity on that side (Fig. $6 C$ ). The area under the curve 
Figure 6. Neurotransmitters mediating inputs from the rhythm-generating network on one side to the opposite side of the spinal cord during the early fetal period. $A$, Left and right ventral root discharges induced by application of $1 \mu \mathrm{M} 5$-HT to left side of the spinal cord at E15.5. Synchronous rhythmic activity is observed on the two sides [5-HT-free side (bottom trace); 5-HT-applied side (top trace)]. Inset shows a schematic drawing indicating the 5-HTapplied side and the side treated either with normal Krebs' $(A, E)$ or with antagonists $(B-D) . B-D$, Effects of application of antagonists, $4 \mathrm{~mm}$ kynurenate $(B), 5 \mu \mathrm{M}$ strychnine $(C)$, and $10 \mu \mathrm{M}$ bicuculline $(D)$, to the 5-HT-free side (bottom trace) in the same preparation as in $A$. $E$, The discharges recorded after washout of antagonists. $F$, Changes in area of integrated ventral root discharges on the 5-HT-free side induced by application of antagonists to that side at E15.5. For the purposes of $F$, the responses on the 5-HT-free side of the cord recorded before any application of antagonists $(A)$ were taken as the "control" responses $(100 \%)$.
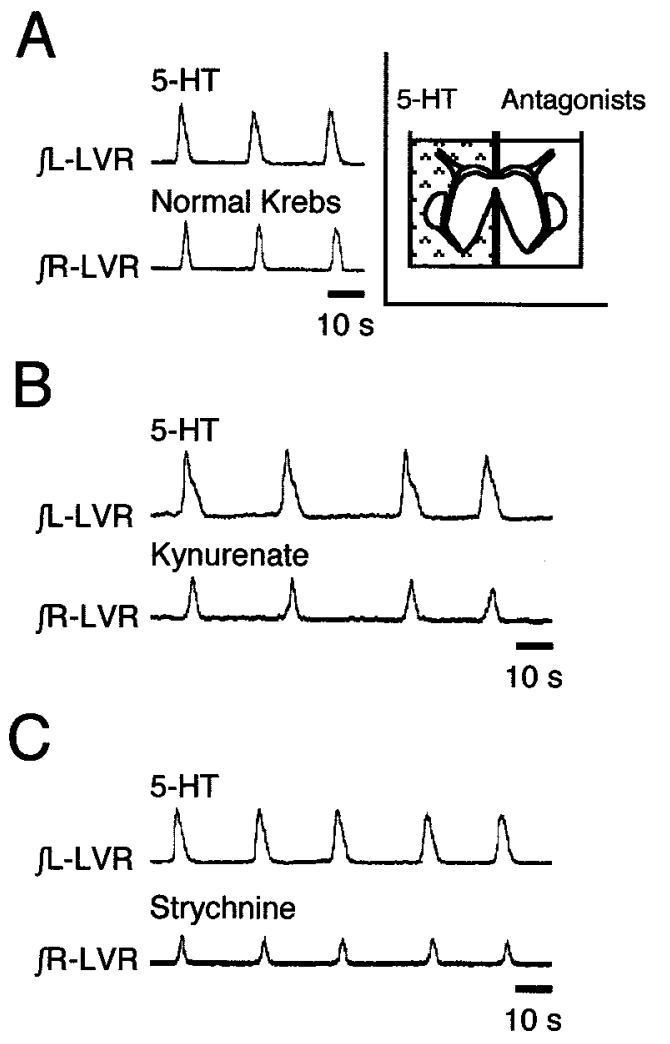
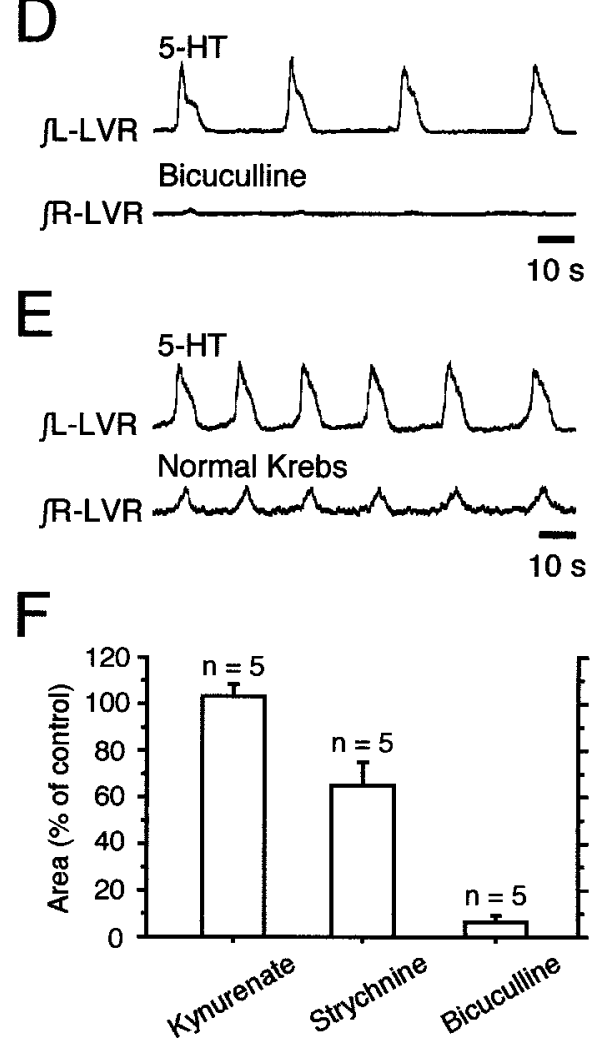

for a single burst was reduced to $65.1 \pm 9.8 \%$ of control $(n=5)$ (Fig. $6 F$ ) by application of strychnine, indicating that glycine mediates part of the left-right coordination of the rhythmic activity. On the other hand, bicuculline $(10 \mu \mathrm{M})$, a $\mathrm{GABA}_{\mathrm{A}}$ receptor antagonist, when applied to the 5-HT-free side blocked the rhythmic activity on that side (Fig. $6 D$ ), the area of the burst being reduced to $7.0 \pm 2.3 \%$ of control $(n=5)$ (Fig. $6 F)$. Similar results were obtained on application of another $\mathrm{GABA}_{\mathrm{A}}$ receptor antagonist, picrotoxin $(20 \mu \mathrm{M})$ (burst area, $6.5 \pm 2.7 \%$ of control; $n=4$ ) (Fig. $7 B, E$ ). To examine whether the effects of $\mathrm{GABA}_{\mathrm{A}}$ receptor antagonists on the rhythmic activity induced on the 5-HT-free side are caused by the blockade of the rhythmgenerating network itself, $\mathrm{GABA}_{\mathrm{A}}$ receptor antagonists were applied to the spinal cord preparation that was split into a hemicord (Fig. 7C). The area of the burst of 5-HT-induced rhythmic activity is little affected by application of picrotoxin $(97.5 \pm 2.8 \%$ of the control; $n=6$ ) (Fig. $7 D, E)$ or bicuculline $(96.9 \pm 2.6 \%$ of the control; $n=3)$. These results indicate that the decrease of the rhythmic activity induced on the 5-HT-free side in the split-bath setup by $\mathrm{GABA}_{\mathrm{A}}$ receptor antagonists is attributable mainly to blockade of the commissural inputs rather than to the effect of the rhythm-generating network itself on the 5-HT-free side. These results suggest that synaptic transmission from the rhythmgenerating network on one side of the spinal cord to the contralateral side is mediated mainly by $\mathrm{GABA}_{\mathrm{A}}$ receptors at early fetal stages.

\section{Neuronal mechanisms generating left-right alternation at the late fetal stages}

The pattern of the 5-HT-induced rhythmic activity becomes alternate between the left and right ventral roots at and after E18.5, as shown in Figure $1 B$. This alternate pattern was not changed by a lesion of the dorsal commissure at E20.5 $(n=5)$
(Fig. $8 B$ ). On the other hand, after a lesion of the ventral commissure, although rhythmic activity could still be observed, the two sides were dissociated $(n=5)$ (Fig. $8 C$ ). These results suggest that neuronal connections through the ventral commissure mediate left-right alternation as well as left-right synchronization observed at earlier fetal stages. This is also in agreement with the results in neonatal rat (Kjaerulff and Kiehn, 1996). In the longitudinal split-bath setup, perfusion of both sides with 5-HT induced alternate rhythmic activity between the left and right ventral roots (Fig. $8 D$ ), indicating that the left-right connection is maintained in this setup. However, in contrast to the situation at E15.5, bath application of 5-HT to one side did not induce any rhythmic activity in the ventral roots on the 5-HT-free side in any of the preparations examined $(n=5)$ (Fig. $8 E$ ), suggesting that the nature of the commissural inputs from the rhythm-generating network has changed by this stage.

To identify the neurotransmitter mediating the left-right alternation, we studied 5-HT-induced rhythmic activity in the isolated spinal cord preparation at E18.5 and E20.5 in a non-split-bath setup (Fig. 9A,D). The rhythmic activity was left-right synchronized after application of bicuculline $(10 \mu \mathrm{M})(n=6)$ (Fig. $9 B)$ or picrotoxin $(20 \mu \mathrm{M})(n=6$; data not shown) in all preparations examined at E18.5. These results indicate that synaptic transmission via $\mathrm{GABA}_{\mathrm{A}}$ receptors plays an important role in the generation of the alternate left-right pattern in the ventral roots at this age. However, at E20.5, bicuculline $(10 \mu \mathrm{M})$ had no such effect in five of seven preparations (Fig. $9 E$ ), although it did change the pattern from alternate to synchronous in the other two preparations. On the other hand, strychnine $(1-5 \mu \mathrm{M})$ changed the pattern from alternate to synchronous both at E18.5 $(n=8)($ Fig. $9 C)$ and at E20.5 $(n=11)$ (Fig. $9 F)$. Finally, we tested the effects of bicuculline and strychnine on the alternate rhythm on postnatal 

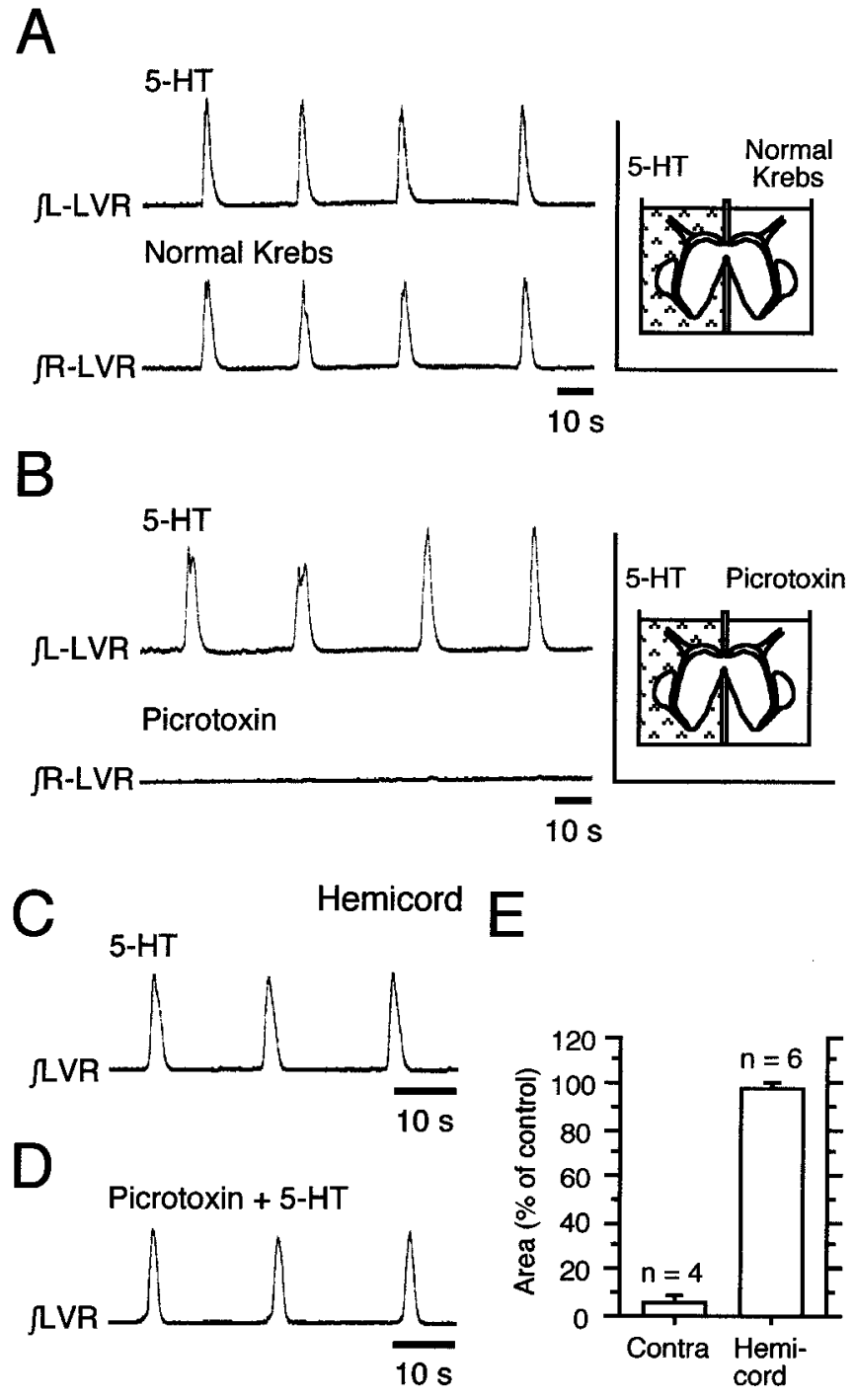

Figure 7. Effect of picrotoxin on rhythm-generating networks. $A, B$, Effects of application of $20 \mu \mathrm{M}$ picrotoxin on the 5-HT-free side $(B)$ in the longitudinal split-bath setup and the control $(A)$ at E15.5. $C, D$, Effects of application of $20 \mu \mathrm{M}$ picrotoxin on 5-HT-induced rhythmic activity in the hemicord at E15.5. E, Change in area of integrated ventral root discharges on the 5-HT-free side induced by application of picrotoxin to that side (Contra) and change in that on the 5-HT-induced rhythmic activity in the hemicord. The responses recorded before application of picrotoxin were taken as "control" responses $(100 \%)$.

day 0 . Bicuculline $(10 \mu \mathrm{M})$ did not change the alternate pattern in any of the preparations examined, but strychnine $(1 \mu \mathrm{M})$ changed it from alternate to synchronous in all preparations $(n=6$; data not shown). These results suggest that glycinergic synaptic transmission becomes the dominant force in the generation of the alternate left-right pattern in the ventral roots in the course of development.

In summary, synaptic transmission via $\mathrm{GABA}_{\mathrm{A}}$ receptors, which coordinates rhythmic activity between the left and right sides of the spinal cord, seems to change from excitatory to inhibitory as development progresses. This change parallels the developmental change in the locomotive pattern from synchronous to alternate. Moreover, an inhibitory component involving glycinergic transmission is added to the one exerted via $\mathrm{GABA}_{\mathrm{A}}$
A

Intact

B

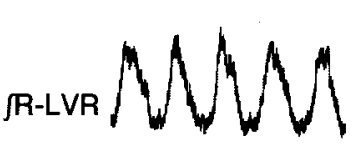

Dorsal commissure cut

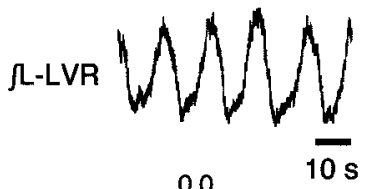

JR-LVR W
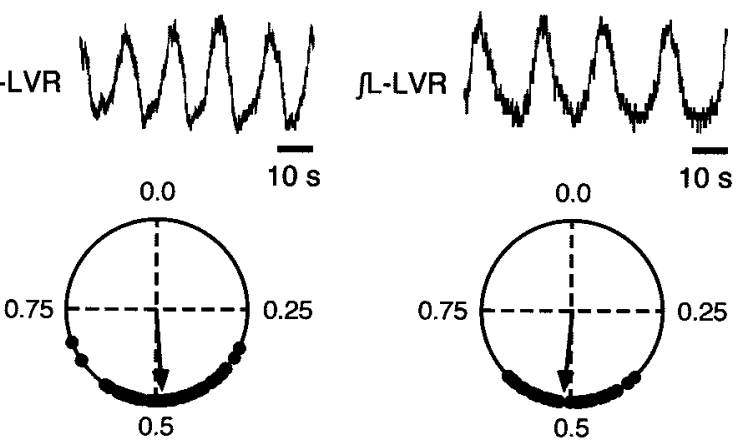

$\mathrm{C}_{\text {Ventral commissure cut }}$

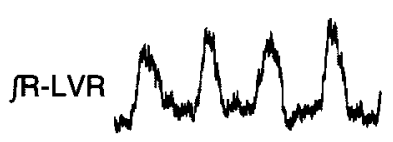

D

Split-bath

5-HT
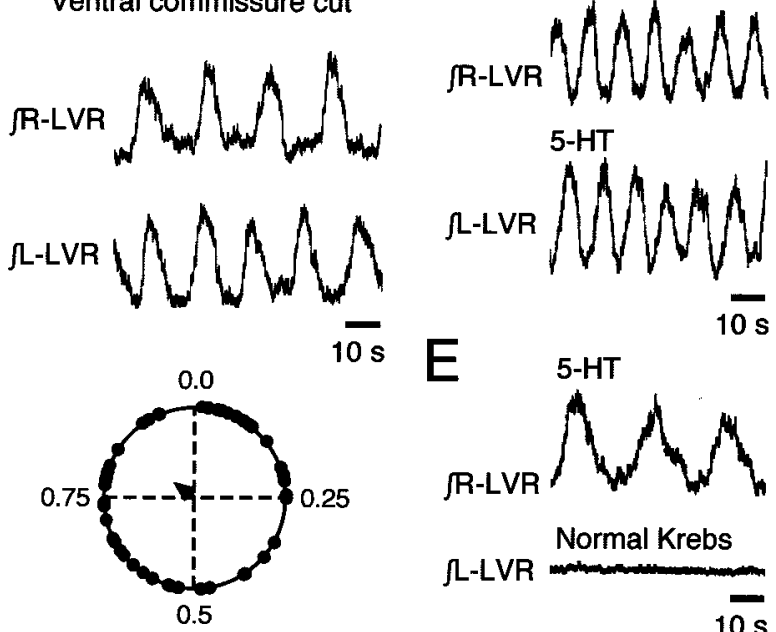

E
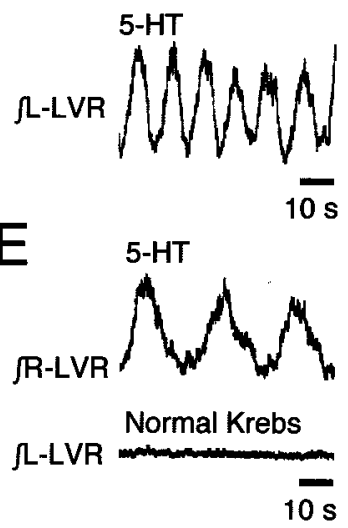

Figure 8. Connection mediating alternating rhythmic activity between left and right spinal cord during the late fetal period. $A-C$, Effects of lesion of the dorsal commissure $(B)$ or ventral commissure $(C)$ on the 5-HT-induced rhythmic activity $(A)$ at E20.5. The rhythmic activity was induced by $20 \mu \mathrm{M} 5$-HT. $A-C$, Bottom panels show phase lags between the left and right sides. The circular plot is based on 10 phase values from each preparation. Data from five tested preparations were pooled and displayed as the left-right circular phase diagram. There were no significant differences among the five preparations. $D, E, 5$-HT-induced discharges in the longitudinal split-bath setup at E20.5. Shown are the effects of application of $20 \mu \mathrm{M} 5$-HT on both sides $(D)$ or on one side (the right) (top trace) $(E)$ in the same preparation.

receptors, and glycinergic inhibition becomes dominant toward birth.

\section{DISCUSSION}

In this study, we made recordings of rhythmic activity from commissural neurons coordinating rhythmic activity between the left and right side of the developing mammalian spinal cord. Furthermore, we provided evidence that changes in the function of GABAergic synaptic transmission from excitatory to inhibitory during fetal development may be responsible for the change in the spatial pattern of the rhythmic locomotor activity from left-right synchronous to alternate. 


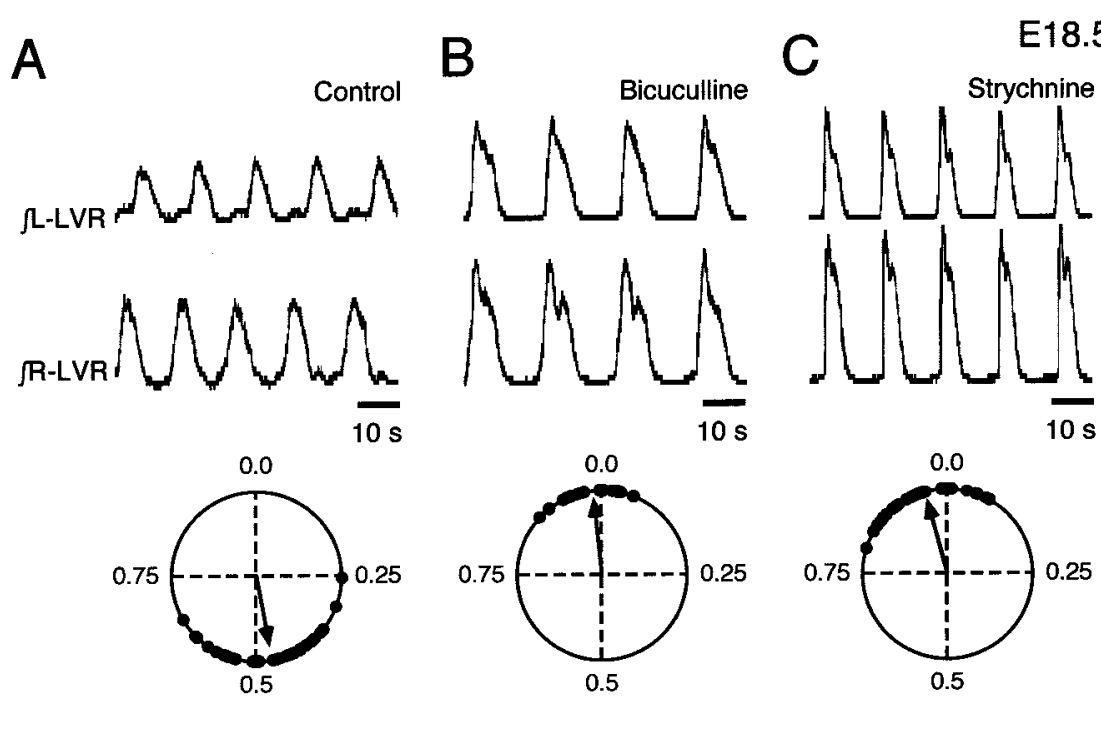

Figure 9. Neurotransmitters mediating reciprocal inhibition during left and right alternation at late fetal stages. $A-C$, Effects of application of $10 \mu \mathrm{M}$ bicuculline $(B)$ or $5 \mu \mathrm{M}$ strychnine $(C)$ on the ventral root discharges $(A)$ induced by $20 \mu \mathrm{M}$ 5-HT at E18.5. $D-F$, Effects of application of $10 \mu \mathrm{M}$ bicuculline $(E)$ or $5 \mu \mathrm{M}$ strychnine $(F)$ on the ventral root discharges $(D)$ induced by $20 \mu \mathrm{M} 5-\mathrm{HT}$ at E20.5. Bottom panels show phase lags between the left and right sides. The circular plot is based on 10 phase values from each preparation. Data from five tested preparations were pooled and displayed as the left-right circular phase diagram. For the circular plot expressing effects of bicuculline at E20.5, results of five preparations in which the pattern was not changed by bicuculline were used. There were no significant differences among the five preparations.

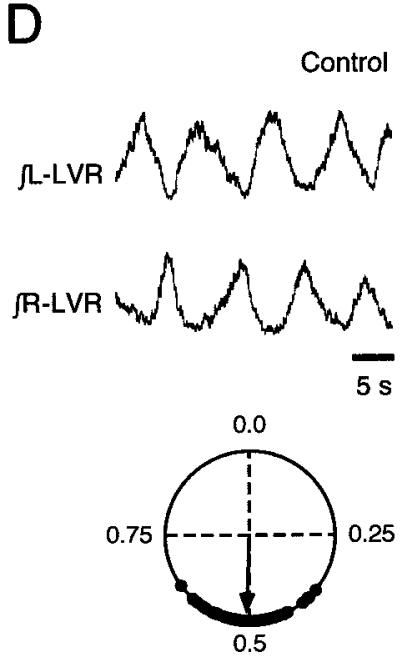

$E$

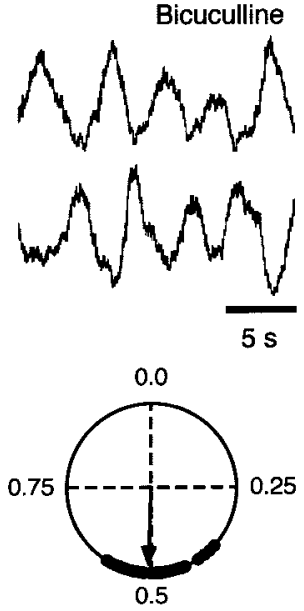

E18.5

F

E20.5
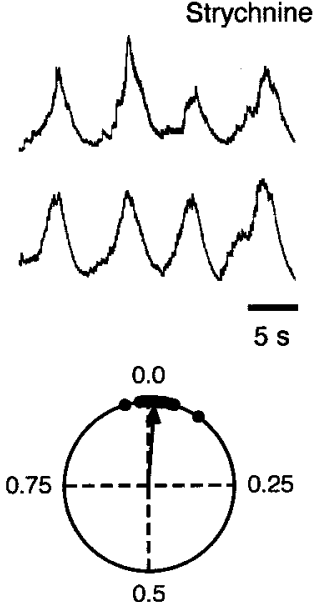

Results of calcium imaging of the commissural neurons suggested that $>80 \%$ of these neurons are rhythmically active during 5-HT-induced rhythmic motor activity at the early fetal stage. We found that cell bodies of these commissural neurons were located mainly in the medial part of the intermediate zone and the medial part of the ventral horn in the lumbar spinal cord at E15.5-16.5. Interestingly, the commissural neurons seem to have already settled into regions similar to the ones they occupy in the neonatal spinal cord (Eide et al., 1999), although some of the spinal neurons are still undergoing migration and have not reached their final destination (Nornes and Das, 1974). It has also been shown in the thoracic cord that the commissural neurons are close to their final locations by E15 (Silos-Santiago and Snider, 1992). In neonatal rats, neuronal populations located in the ventromedial part of the lumbar cord seem to contain essential elements that generate coordinated left-right rhythmic activity (Kjaerulff and Kiehn, 1996), raising the possibility that the commissural neurons located in this region are part of the rhythm-generating network (Eide et al., 1999). In other vertebrates, commissural neurons that are phasically active during rhythmic motor activity have been found in lamprey spinal cord (Buchanan and Cohen, 1982) and in Xenopus embryo spinal cord (Soffe et al., 1984). These commissural neurons project to the contralateral side of the spinal cord and connect to various types of neurons that together make up the rhythm-generating network (Buchanan, 1982). In the fetal rat spinal cord at E15.5, activation of the rhythm-generating network on one side induced rhythmic activity in contralateral motoneurons, indicating that the rhythmically active commissural neurons are mediating the activity to the opposite side. In the neonatal rat, it has been shown that motoneurons receive rhythmic synaptic inputs from the contralateral rhythm-generating network, and some of these inputs are directly from contralateral interneurons (Kjaerulff and Kiehn, 1997), which might be the case in the fetal rat spinal cord. In the present study, rhythmic activity could also be evoked by direct excitation of commissural neurons on the contralateral side. It is likely that the commissural neurons are activated tonically rather than rhythmically in this case, because application of muscimol with TTX induced a long-lasting tonic $\left[\mathrm{Ca}^{2+}\right]_{\mathrm{i}}$ elevation in the commissural neurons. Interestingly, an increase of extracellular $\mathrm{K}^{+}$concentration up to 8-20 mm could evoke the rhythmic activity in a hemicord of fetal rats (K. Nakayama, unpublished observation), suggesting that tonic excitatory inputs can induce the rhythmic activity as a result of network depolarization.

In the experiments that used a longitudinal split-bath setup, we cannot completely exclude the possibility that the agonists diffused across the preparation to the other side. However, we consider this possibility unlikely on the basis of the following 
observations. (1) Application of 5-HT with $\mathrm{Ca}^{2+}$-free Krebs' solution on one side did not induce rhythmic activity on the opposite side, which was perfused with normal Krebs' solution. (2) No rhythmic activity was recorded on the 5-HT-free side when we used a preparation during which the left and right sides were connected via the dorsal commissure instead of the ventral commissure (K. Nakayama, unpublished observation). Therefore, we suggest that the rhythmic activity on the 5-HT-free side was induced primarily by synaptic inputs via commissural neurons from the rhythm-generating networks on the 5-HT-applied side.

Our results suggest that the neuronal pathways from the rhythm-generating network on one side to the motoneurons on the opposite side of the spinal cord rely mainly on mediation by $\mathrm{GABA}_{\mathrm{A}}$ receptors at early fetal stages. Interestingly, it has been found that a substantial number of commissural neurons located in the ventral region transiently show immunoreactivity for glutamic acid decarboxylase (GAD) at early fetal stages (Phelps et al., 1999). These GAD-positive commissural neurons may be one candidate for the neurons connecting the rhythm-generating networks across the cord. In the present study, $\mathrm{GABA}_{\mathrm{A}}$ receptor antagonists failed to block completely the contralateral rhythm at early fetal stage. Another neurotransmitter, glycine, could be involved in the left-right coordination as well, because bath application of strychnine attenuated the contralateral rhythmic activity. In the Xenopus embryo spinal cord, glycinergic commissural interneurons form direct connections between the left and right rhythm-generating networks (Soffe and Roberts, 1982).

The excitatory effect of GABAergic and glycinergic synaptic transmission in the spinal cord during the early fetal period is likely to be caused by the high intracellular concentration of $\mathrm{Cl}^{-}$ ions (Wu et al., 1992; Kulik et al., 2000). Such excitation causes a rise in $\left[\mathrm{Ca}^{2+}\right]_{\mathrm{i}}$ in fetal spinal neurons (Reichling et al., 1994; Kulik et al., 2000) that could induce a clustering of receptors at postsynaptic sites in cultured spinal neurons (Kirsch and Betz, 1998). Moreover, elevations in the $\left[\mathrm{Ca}^{2+}\right]_{i}$ of the developing neuron are known to be involved in controlling the outgrowth of its dendrites and axons (Kater et al., 1988; Metzger et al., 1998), and this could be essential for the formation of the inhibitory pathway between the rhythm-generating networks.

The spatial pattern of the 5-HT-induced rhythmic activity changes from left-right synchronous to alternate by E18.5. The alternate pattern was changed to synchronous by bath application of bicuculline at E18.5, indicating that, at this stage, $\mathrm{GABA}_{\mathrm{A}}$ receptors are mediating reciprocal inhibition between the two sides. Interestingly, similar developmental changes in the function of GABA from excitatory to inhibitory can be seen in other neuronal networks in the rat lumbar spinal cord during this period. For instance, Wu et al. (1992) showed that although both strychnine and bicuculline block dorsal root-evoked responses at E16-17, the responses evoked at E18-19 are enhanced. They also showed that the amplitude of the depolarizations induced by GABA and glycine decreases toward birth. It is probable that this developmental decrease in the magnitude of the GABA-induced depolarizations correlates with an increase in the expression of an outwardly directed $\mathrm{Cl}^{-}$pump $\left[\mathrm{Cl}^{-}\right.$-extruding $\mathrm{K}^{+} / \mathrm{Cl}^{-}$cotransporter (KCC2)], as it does in the developing rat hippocampus (Rivera et al., 1999). In a recent study, it was shown that in cultured hippocampal neurons, the GABA-induced increase in $\left[\mathrm{Ca}^{2+}\right]_{i}$ induces KCC2 expression, which switches the neuronal response to GABA from excitatory to inhibitory (Ganguly et al., 2001). This might also be the case in the developing rat spinal cord.

5-HT induces synchronous activity in the presence of strych- nine or bicuculline after E18.5, indicating that the rhythmgenerating networks on both sides are connected by neuronal mechanisms other than the GABAergic or glycinergic synaptic transmission during this period. A likely candidate mediating this connection is glutamatergic excitatory synaptic transmission, which is involved in rhythmic synaptic inputs to the motoneurons from the contralateral side in neonatal rats (Kjaerulff and Kiehn, 1997). In neonatal rats, it has been shown that some of the dendrites of lumbar motoneurons cross the midline (Lindsay et al., 1991), which could be an alternative pathway connecting the left-right motor activity. However, the functional significance of these dendrites remains unclear, and our present results indicate that rhythmic activity on one side is transmitted to contralateral motoneurons via synaptic connections within the same side of the fetal spinal cord.

At E20.5, bicuculline failed to change the alternate pattern in $\sim 70 \%$ of the preparations examined. In neonatal rats, bicuculline (up to $10 \mu \mathrm{M}$ ) does not change the phase relationship in NMA ( $N$-methyl-D,L-aspartate)-induced left-right alternate rhythmic activity (Cazalets et al., 1998). Bath application of strychnine, in contrast, changed the alternate pattern to a synchronous one in all preparations examined at and after E18.5. This is in agreement with results in the neonatal rat showing that rhythmic IPSPs evoked in the motoneurons by activation of the contralateral rhythm-generating network are more sensitive to strychnine than to bicuculline (Kjaerulff and Kiehn, 1997). However, recent studies suggest that synapses releasing both GABA and glycine are on the motoneurons in fetal (Gao et al., 2001) and neonatal rats (Jonas et al., 1998), and because it has been shown that strychnine could partially block GABAergic synapses (Jonas et al., 1998), it is possible that $\mathrm{GABA}_{\mathrm{A}}$ receptors are involved in the commissural inputs at this stage as well. However, the number of commissural neurons showing GAD immunoreactivity decreases from early fetal stages toward birth (Phelps et al., 1999), and an increase in the number of functional glycinergic synapses and a relative decrease in GABAergic synaptic inputs to lumbar motoneurons have been shown to occur in the late fetal stage (Gao et al., 2001). These results indicate that glycinergic rather than GABAergic synaptic transmission becomes the dominant force in the left-right alternation shortly before birth. Such a developmental shift from $\mathrm{GABA}_{\mathrm{A}}$ receptor-mediated to glycine receptormediated synaptic transmission has also been documented in the developing central auditory system of gerbils (Kotak et al., 1998).

\section{REFERENCES}

Batschelet E (1981) Circular statistics in biology (Sibson R, Cohen JE, eds). New York: Academic.

Ben-Ari Y, Cherubini E, Corradetti R, Gaiarsa JL (1989) Giant synaptic potentials in immature rat CA3 hippocampal neurones. J Physiol (Lond) 416:303-325.

Buchanan JT (1982) Identification of interneurons with contralateral, caudal axons in the lamprey spinal cord: synaptic interactions and morphology. J Neurophysiol 47:961-975.

Buchanan JT, Cohen AH (1982) Activities of identified interneurons, motoneurons, and muscle fibers during fictive swimming in the lamprey and effects of reticulospinal and dorsal cell stimulation. J Neurophysiol 47:948-960.

Cazalets JR, Sqalli-Houssaini Y, Clarac F (1992) Activation of the central pattern generators for locomotion by serotonin and excitatory amino acids in neonatal rat. J Physiol (Lond) 455:187-204.

Cazalets JR, Bertrand S, Sqalli-Houssaini Y, Clarac F (1998) GABAergic control of spinal locomotor networks in the neonatal rat. Ann NY Acad Sci 860:168-180.

Cowley KC, Schmidt BJ (1995) Effects of inhibitory amino acid antagonists on reciprocal inhibitory interactions during rhythmic motor activity in the in vitro neonatal rat spinal cord. J Neurophysiol 74:1109-1117

Davidoff RA, Hackman JC (1983) Drugs, chemicals, and toxins: their 
effects on the spinal cord. In: Handbook of the spinal cord (Davidoff RA, ed), pp 409-476. New York: Marcel Dekker.

Ehrlich I, Lohrke S, Friauf E (1999) Shift from depolarizing to hyperpolarizing glycine action in rat auditory neurones is due to agedependent $\mathrm{Cl}^{-}$regulation. J Physiol (Lond) 520:121-137.

Eide AL, Glover J, Kjaerulff O, Kiehn O (1999) Characterization of commissural interneurons in the lumbar region of the neonatal rat spinal cord. J Comp Neurol 403:332-345.

Eilers J, Plant TD, Marandi N, Konnerth A (2001) GABA-mediated $\mathrm{Ca}^{2+}$ signalling in developing rat cerebellar Purkinje neurones. J Physiol (Lond) 536:429-437.

Ganguly K, Schinder AF, Wong ST, Poo M (2001) GABA itself promotes the developmental switch of neuronal GABAergic responses from excitation to inhibition. Cell 105:521-532.

Gao BX, Stricker C, Ziskind-Conhaim L (2001) Transition from GABAergic to glycinergic synaptic transmission in newly formed spinal networks. J Neurophysiol 86:492-502.

Grillner S (1975) Locomotion in vertebrates: central mechanisms and reflex interaction. Physiol Rev 55:247-304.

Grillner S (1985) Neurobiological bases of rhythmic motor acts in vertebrates. Science 228:143-149.

Iizuka M, Nishimaru H, Kudo N (1998) Development of the spatial pattern of 5-HT-induced locomotor rhythm in the lumbar spinal cord of rat fetuses in vitro. Neurosci Res 31:107-111.

Jonas P, Bischofberger J, Sandkuhler J (1998) Corelease of two fast neurotransmitters at a central synapse. Science 281:419-424.

Kater SB, Mattson MP, Cohan C, Connor J (1988) Calcium regulation of the neuronal growth cone. Trends Neurosci 11:315-321.

Kiehn O, Kjaerulff O (1996) Spatiotemporal characteristics of 5-HT and dopamine-induced rhythmic hindlimb activity in the in vitro neonatal rat. J Neurophysiol 75:1472-1482.

Kiehn O, Hounsgaard J, Sillar KT (1997) Basic building blocks of vertebrate spinal central pattern generators. In: Neurons, networks, and motor behavior (Stein PSG, Grillner S, Selverston AI, Stuart DG, eds), pp 47-59. Cambridge, MA: MIT.

Kirsch J, Betz H (1998) Glycine-receptor activation is required for receptor clustering in spinal neurons. Nature 392:717-720.

Kjaerulff O, Kiehn O (1996) Distribution of networks generating and coordinating locomotor activity in the neonatal rat spinal cord in vitro: a lesion study. J Neurosci 16:5777-5794.

Kjaerulff O, Kiehn O (1997) Crossed rhythmic synaptic input to motoneurons during selective activation of the contralateral spinal locomotor network. J Neurosci 17:9433-9447.

Koshiya N, Smith JC (1999) Neuronal pacemaker for breathing visualized in vitro. Nature 400:360-363.

Kotak VC, Korada S, Schwartz IR, Sanes DH (1998) A developmental shift from GABAergic to glycinergic transmission in the central auditory system. J Neurosci 18:4646-4655.

Kudo N, Yamada T (1987) $N$-methyl-D, L-aspartate-induced locomotor activity in a spinal cord-hindlimb muscles preparation of the newborn rat studied in vitro. Neurosci Lett 75:43-48.

Kulik A, Nishimaru H, Ballanyi K (2000) Role of bicarbonate and chloride in GABA- and glycine-induced depolarization and $\left[\mathrm{Ca}^{2+}\right]_{\mathrm{i}}$ rise in fetal rat motoneurons in situ. J Neurosci 20:7905-7913.

Leinekugel X, Tseeb V, Ben-Ari Y, Bregestovski P (1995) Synaptic $\mathrm{GABA}_{\mathrm{A}}$ activation induces $\mathrm{Ca}^{2+}$ rise in pyramidal cells and interneu- rons from rat neonatal hippocampal slices. J Physiol (Lond) 487: 319-329.

Li YX, Schaffner AE, Walton MK, Barker JL (1998) Astrocytes regulate developmental changes in the chloride ion gradient of embryonic rat ventral spinal cord neurons in culture. $J$ Physiol (Lond) 509:847-858.

Lindsay AD, Greer JJ, Feldman JL (1991) Phrenic motoneuron morphology in the neonatal rat. J Comp Neurol 308:169-179.

Metzger F, Wiese S, Sendtner M (1998) Effect of glutamate on dendritic growth in embryonic rat motoneurons. J Neurosci 18:1735-1742.

Nakayama K, Nishimaru H, Kudo N (2001a) Neuronal connection coordinating the left/right rhythmic activity in the fetal rat spinal cord. Soc Neurosci Abstr 27:805.

Nakayama K, Nishimaru H, Kudo N (2001b) Developmental changes in 5-hydroxytryptamine-induced rhythmic activity in the spinal cord of rat fetuses in vitro. Neurosci Lett 307:1-4.

Nishimaru H, Kudo N (2000) Formation of the central pattern generator for locomotion in the rat and mouse. Brain Res Brain Res Bull 53:661-669.

Nishimaru H, Iizuka M, Ozaki S, Kudo N (1996) Spontaneous motoneuronal activity mediated by glycine and GABA in the spinal cord of rat fetuses in vitro. J Physiol (Lond) 497:131-143.

Nornes HO, Das GD (1974) Temporal pattern of neurogenesis in spinal cord of rat. I. An autoradiographic study - time and sites of origin and migration and settling patterns of neuroblasts. Brain Res 73:121-138.

Ozaki S, Yamada T, Iizuka M, Nishimaru H, Kudo N (1996) Development of locomotor activity induced by NMDA receptor activation in the lumbar spinal cord of the rat fetus studied in vitro. Brain Res Dev Brain Res 97:118-125.

Phelps PE, Alijani A, Tran TS (1999) Ventrally located commissural neurons express the GABAergic phenotype in developing rat spinal cord. J Comp Neurol 409:285-298.

Reichling DB, Kyrozis A, Wang J, MacDermott AB (1994) Mechanisms of GABA and glycine depolarization-induced calcium transients in rat dorsal horn neurons. J Physiol (Lond) 476:411-421.

Rivera C, Voipio J, Payne JA, Ruusuvuori E, Lahtinen H, Lamsa K, Pirvola U, Saarma M, Kaila K (1999) The $\mathrm{K}^{+} / \mathrm{Cl}^{-}$co-transporter KCC2 renders GABA hyperpolarizing during neuronal maturation. Nature 397:251-255.

Silos-Santiago I, Snider WD (1992) Development of commissural neurons in the embryonic rat spinal cord. J Comp Neurol 325:514-526.

Smith JC, Feldman JL (1987) In vitro brainstem-spinal cord preparations for study of motor systems for mammalian respiration and locomotion. J Neurosci Methods 21:321-333.

Soffe SR, Roberts A (1982) Tonic and phasic synaptic input to spinal cord motoneurons during fictive locomotion in frog embryos. J Neurophysiol 48:1279-1288.

Soffe SR, Clarke JD, Roberts A (1984) Activity of commissural interneurons in spinal cord of Xenopus embryos. J Neurophysiol 51:1257-1267.

Wu WL, Ziskind-Conhaim L, Sweet MA (1992) Early development of glycine- and GABA-mediated synapses in rat spinal cord. J Neurosci 12:3935-3945.

Young AB, MacDonald RL (1983) Glycine as a spinal cord neurotransmitter. In: Handbook of the spinal cord (Davidoff RA, ed), pp 1-43. New York: Marcel Dekker. 